\title{
VISUAL ACUITY AND IMAGE QUALITY IN FIVE DIFFRACTIVE INTRAOCULAR LENSES
}

Short title: Visual acuity and image quality in five diffractive intraocular lenses

Genís Cardona ${ }^{\mathrm{a}}$, Fidel Vega ${ }^{\mathrm{a}}$, Miguel A. Gil ${ }^{\mathrm{b}}$, Consuelo Varóna, José A. Buil' $^{b}$, María S. Millánª

\author{
a Applied Optics and Image Processing Group, Department of \\ Optics and Optometry, Universitat Politècnica de Catalunya . \\ BarcelonaTech, Terrassa, Spain \\ b Ophthalmology Department, Santa Creu and Sant Pau Hospital, \\ Barcelona, Universitat Autònoma de Barcelona, Spain
}

Word count: 4066

Corresponding Author: $\quad \begin{aligned} & \text { Genís Cardona (genis.cardona@upc.edu) } \\ & \text { Terrassa School of Optics and Optometry } \\ & \text { Violinista Vellsolà, } 37 \\ & \text { E08222 Terrassa, Catalonia, Spain } \\ & \text { Telephone: }+34937398774 \\ & \text { Fax: }+34937398301\end{aligned}$




\section{ABSTRACT}

Introduction: To compare objective image quality at distant, intermediate and near foci with the corresponding visual acuity (VA) in patients symmetrically implanted with five different diffractive multifocal intraocular lenses (MIOLs) (ReSTOR SV25T0, Tecnis ZKB00, Tecnis ZLB00, ATLISA809 and ATLISATri 839MP) and a monofocal lens (Tecnis ZA9003), three months after cataract intervention.

Methods: Objective image quality, measured as the area under the modulation transfer function curve (AMTF), was tested in-vitro in an eye model. Besides, corrected distance visual acuity (CDVA), distance corrected intermediate and near visual acuities (DCIVA and DCNVA) were assessed in a group of 79 patients, randomly implanted with one of the lenses.

Results: Image quality and VA at the distant focus was good for all lens designs, but was similarly compromised at the intermediate focus, where the best DCIVA corresponded to the low add ZKB00. At the near focus, the monofocal lens and the distance dominant SV25T0 had the worst AMTF values, with the ZLB00 presenting the best DCNVA. The relationship between AMTF and visual acuity was found not to be linear, with visual acuity being similarly good for AMTF values over a certain threshold.

Conclusion: Visual acuity of pseudophakic patients reflected the optical quality of the specific IOL design within a certain range of measurements, beyond which maximum visual acuity is limited by other ocular, optical and neuropsychophysical factors. 


\section{KEYWORDS}

Diffractive optics; Intraocular lens; Multifocal; Objective image quality; Visual acuity 


\section{INTRODUCTION}

Given the growing visual requirements at near and intermediate distances, it is nowadays common practice in cataract surgery to implant multifocal intraocular lenses (MIOLs), although monofocal still account for a majority of lens implantations (1). Multifocal intraocular lenses aim to provide patients with spectacle independence at any distance $(2,3)$. Although many different lens designs exist, when compared with refractive MIOLs, diffractive designs, particularly those with aspheric profiles, have been documented to provide superior visual acuity (VA) at far and near distances $(4,5)$ and better contrast sensitivity (5-10). Recently, trifocal lens designs have been introduced to improve vision at intermediate distances (11).

Optical quality of intraocular lenses (IOLs) may be assessed objectively, at an optical bench, or subjectively, in which one or various visual function parameters may be explored. Optical bench testing offers the advantage of allowing for a fine control of factors such as pupil diameter, lens alignment or the amount of spherical aberration of the artificial cornea used in the experimental setup. Previous research employing an optical bench has explored through-focus image quality and modulation transfer function (MTF) (12-18), energy distribution at far and near foci (19), the effect of pupil size $(4,15,20)$ and the formation of halos in diffractive MIOLs (14). As far as we know, only some of these authors have also investigated the correlation between optical bench performance and VA $(17,18)$. Thus, Felipe and coworkers (17) examined the relationship between photopic and mesopic visual acuities of patients implanted with three models of MIOLs (one refractive, and two diffractive) and the average MTF values of the curves obtained in-vitro at 
the distance, intermediate and near planes of the lenses. The authors reported that a decrease of $25 \%$ or more in the average MTF value was needed to elicit a significant worsening in VA (17) and also inferred linear correlations between VA and average MTF, with $R^{2}$ values of 0.91 and 0.88 for photopic and mesopic conditions, respectively. Similarly, Plaza-Puche and colleagues compared the through-focus image quality obtained at the optical bench with clinically assessed defocus curves in patients implanted with two MIOLs of different design (18) (one refractive varifocal and one diffractive trifocal) and a monofocal IOL. An ad hoc image quality metric based on cross-correlation coefficients was used to describe through-focus image quality, whereupon strong correlations were reported, for photopic pupil sizes, between this parameter and logMAR VA values ( $R^{2}$ of 0.85$)$.

It was therefore the aim of the present study to further evaluate the correspondence and to analyze the linear relationship between objective optical quality and distance, intermediate and near VA. For this purpose, this relationship was explored in five diffractive MIOLs, different from those examined in previous research $(17,18)$. Moreover, one monofocal lens was also included to investigate the range of optical quality and thus to test the upper limit of the documented linearity. Objective optical quality was measured with the area under the MTF curve (AMTF) computed for the range of frequencies from 0 to $100 \mathrm{c} / \mathrm{mm}$, and VA was obtained from 79 eyes implanted with these lenses. 


\section{METHODS}

\section{Study Sample}

Seventy-nine participants were consecutively recruited for this study from those attending the Ophthalmology Department of Santa Creu i Sant Pau Hospital, Barcelona, for routine cataract intervention. Only patients aged over 60 years, with bilateral lens implantation and preoperative refractive astigmatism of $1.5 \mathrm{D}$ or less were included in the study. Exclusion criteria were history of glaucoma, retinal detachment or other retinal abnormalities, severe dry eye, corneal opacities or disease, previous corneal or intraocular surgery, abnormal pupil response and diabetes mellitus, as well as surgical complications, pupillary trauma or vitreous loss. Inability to place the lens in the capsular bag and lens tilt or descentration greater than $0.4 \mathrm{~mm}$ also resulted in exclusion from the study. To allow comparison with the results of the optical bench, only patients with large ( $3.5 \mathrm{~mm} \pm 0.5 \mathrm{~mm})$ natural pupils were included in the study.

All participants provided written informed consent after the nature of the study was explained to them. The study was conducted in accordance with the Declaration of Helsinki tenets of 1975 (as revised in Tokyo in 2004). The study received the approval of the Sant Pau Hospital institutional review board.

\section{Intraocular lenses}

Five different diffractive MIOL designs were evaluated in this study, as well as a monofocal lens. The main characteristics of these IOLs are summarized in

Table 1. Implanted lens power was $20.00 \mathrm{D} \pm 4.00 \mathrm{D}$ in all instances. 


\section{Surgical Technique}

The same experienced surgeon (M.A.G.) completed all surgeries. A main 2.75 $\mathrm{mm}$ clear corneal incision was performed in the steepest corneal meridian, followed by a secondary paired incision at 180 degrees, for corneal astigmatisms over 1.00 D. For those patients with corneal astigmatism lower than $1.00 \mathrm{D}$ incisions did not induce astigmatism. After standard phacoemulsification, IOLs were implanted in the capsular bag using the injectors recommended by each manufacturer. All lens implantations were aimed at emmetropia.

\section{Optical Setup and AMTF measurements}

Optical quality of distance, intermediate and near foci was determined with an optical test bench schematically shown in Figure 1. This experimental setup, which was described in detail elsewhere (19), included a model eye with an artificial cornea and is consistent with the International Organization for Standardization (ISO) 11979-2:2014 (21). It took into consideration the recommendation regarding using a non-aberration free artificial cornea, similar to the average human cornea, for the evaluation of aspheric IOLs. An iris diaphragm, with a variable aperture, is placed in front of the artificial cornea to control the size of the beam arriving at the artificial cornea, and thus the level of spherical aberration introduced by the model eye (without the IOL) (22). To this extent, our artificial cornea provided $+0.27 \mu \mathrm{m}$ of spherical aberration (SA) for a $6.0 \mathrm{~mm}$ pupil diameter. To determine the diameter of the aperture at the plane of the IOL, the diameter of the beam at the IOL plane was calibrated versus the 
diameter of the iris diaphragm. A linear relation between these two parameters was found, in which the diameter of the beam reaching the IOL plane was always 0.5 times larger than that of the iris diaphragm. Subsequently, all pupil diameters are referred to the actual IOL plane instead of the iris plane (19). A green light emitting diode (LED) (LED525E; Thorlabs GmbH, Munich, Germany), with emission centered at $525 \mathrm{~nm}$ and full-width half-maximum spectral bandwidth of $\pm 15 \mathrm{~nm}$, was used to illuminate a four-slit pattern test object for MTF measurement. The text object was located at the front focal plane of a collimator (focal length of $200 \mathrm{~mm}$ ). All the slits in the object pattern had a constant width of $10 \mu \mathrm{m}$. The images of this object formed by the IOLs under study were magnified onto an 8-bit charge-coupled (CCD) camera (Wells Research, Inc., West Covina, CA) with a X10 infinity corrected microscope, which could be moved along the bench axis to locate the best focal planes for each IOL and observation distance. It must be noted that only one lens design, the trifocal ATLISATri, had a defined intermediate focus. Therefore, to test the intermediate focus in the other MIOLs the microscope was positioned at the plane corresponding to half the near add power for each particular lens. In addition, the near plane of the monofocal lens (Tecnis ZA9003) was chosen to match the near plane of the similarly designed Tecnis ZKBOO (add power: +2.75D) and the intermediate plane was tested by taking into consideration half the near add power of the same lens.

The MTF curve was obtained from the Fourier transform of the line spread function of the slit pattern images (23), whereupon the AMTF was determined by integration of the MTF curve between 0 and 100 cycles per millimeter. To allow comparison with previous research (17) it is worth noting that this metric 
differs from the average MTF by a constant factor and, therefore, AMTF and average MTF may be considered equivalent. The best focal planes were experimentally found as those that maximized the AMTF. For each IOL and focus, measurements were conducted with an artificial entrance pupil of $3 \mathrm{~mm}$, which corresponds to approximately $3.5 \mathrm{~mm}$ at the corneal plane, equivalent to the average natural pupil diameter of the sample of patients.

Visual acuity measurements

All examinations were performed 3 months after lens implantation by the same trained optometrist (C.V.), who was unaware of the type of lens implanted to each particular patient. Monocular corrected distance visual acuity (CDVA) was measured in logMAR notation with the Early Treatment Diabetic Retinopathy Study (ETDRS) chart (Optec 6500, Stereo Optical Inc., Chicago, IL.) viewed at $4 \mathrm{~m}$. Distance corrected intermediate (DCIVA) and near (DCNVA) visual acuities were measured at 60 and $40 \mathrm{~cm}$, respectively, with the Snellen chart developed by the Department of Employment and Industry of the Catalan Government, which is in decimal notation. All measurements were conducted under photopic conditions $\left(85 \mathrm{~cd} / \mathrm{m}^{2}\right)$. Pupil diameter was examined with the infrared Colvard pupillometer (Oasis Medical Inc., San Dimas, CA) while participants fixated at a distant target. 
Data Analysis

Statistical analysis of the data was performed with the SPSS software 17.0 for Windows. Only one eye per patient, selected at random, was used for statistical analysis. All data were examined for normality using the Kolmogorov-Smirnov test, which revealed several instances of non-normal distribution. Accordingly, descriptive statistics were summarized as median and range (minimummaximum values). Besides, comparisons between IOL groups were conducted with the Kruskal-Wallis test for independent samples and, when differences reached statistical significance, the Mann-Whitney $U$ test was employed for pair-wise analysis. A p-value of 0.05 or less was considered to denote statistical significance throughout the study. 


\section{RESULTS}

Patients (31 males and 48 females) had a mean age of 73 years (range from 60 to 84 years). A summary of demographic data and CDVA, DCIVA and DCNVA results for each IOL under evaluation, including the monofocal ZA9003, is presented in Table 2. The corresponding AMTF values at each focus are also displayed.

Whereas, no differences in CDVA were found among the groups, statistically significant within-group differences were encountered in DCIVA and DCNVA. Although CDVA was similarly good in all IOLs under evaluation, the monofocal IOL followed by the SV25T0 offered considerably larger AMTF values than the rest of the lenses at the distance focus. In contrast, at the intermediate focus none of the IOLs presented good values of AMTF. Visual acuity at intermediate distance was compromised in all IOLs, with the exception of the ZKB00, which offered relatively good DCIVA. Indeed, the subsequent pair-wise analysis revealed statistically significant differences in DCIVA between the ZKB00 and the SV25T0 $(p=0.002)$, the ATLISA809 $(p=0.001)$ and the ATLISATri $(p=0.008)$. Finally, regarding near vision, when compared with the MIOLs, the monofocal IOL showed the worst performance in terms of AMTF and DCNVA (all $p<0.001$ ). Within the MIOLs, the poorest performance in AMTF and DCNVA (all $p<0.05$ ) corresponded to the SVT250. In addition, the ZKB00 and the ZLB00 had larger AMTF values than the ATLISA809 and the ATLISATri, although these differences were not statistically significant in terms of DCNVA. In order to investigate the relationship between AMTF and VA, the median CDVA, DCIVA and DCNVA values for each IOL under evaluation were plotted 
against the corresponding AMTF values at distance, intermediate and near foci. This plot is shown in Figure 2, displaying an association between AMTF and VA in which, in general, larger values of AMTF correspond to better VA scores (lower logMAR values). However, this association can be thought to be compatible with a linear function only for low values of AMTF. Indeed, an increase in AMTF is reflected in a corresponding increase in VA, albeit at a slower rate. For AMTF values over a certain threshold (about 20), however, changes in VA cannot longer be detected, with VA values remaining almost constant and good (values between 0.1 and 0 logMAR, approximately). Thus, three distinct patterns emerge, as highlighted by colored rectangles in Figure 2. The poor performance of the monofocal lens at near and intermediate distances, particularly in terms of VA, may be observed in the data points located at the superior left area of the figure. In addition, it is worth remarking that the data points of the SV25T0 at near are found close to this area, confirming the limited performance of this MIOL at this distance. Conversely, at distance vision this lens offers the best performance in terms of optical quality after the monofocal lens. 


\section{DISCUSSION}

It was the purpose of this study to examine the relationship between objective image quality values at distance, intermediate and near foci, as measured at the optical bench, and the corresponding VA at far, intermediate and near distances of patients bilaterally implanted with five different diffractive MIOLs, as compared with a monofocal lens group.

Overall, at distance, the best AMTF corresponded to the monofocal lens, followed by the SV25T0 MIOL. All the other MIOLs designs (ZKB00, ZLB00, ATLISA 809 and ATLISA Tri) had a similar performance. The superior optical performance of the SV25T0 at distance in comparison to the rest of MIOLs is in agreement with previous work (24) and is related to the design of this lens, which combines a low add power and central apodized region with a peripheral refractive area to enhance the performance of its distance focus for large pupils. In addition, Carson et al also reported better performance at the optical bench of the SV25T0 over the ATLISATri (16), although in contrast with that study, in which a lower AMTF value was associated with reduced VA, our results did not show any statistical difference in CDVA among IOLs. Indeed, as noted in Figure 2, for AMTF values roughly over 20 , the corresponding VA outcomes were found to be equally good, with differences among the lenses of less than $0.1 \log$ MAR, which are small enough to be considered as clinically significant (25).

As previously mentioned, few authors have investigated the correlation between IOL performance at the optical bench and VA $(17,18)$. Felipe et al $(17)$ only considered three models of MIOLs (one refractive, and two diffractive), a choice that limited the range of available AMTF values, with a maximum AMTF score 
of 46 for a $3 \mathrm{~mm}$ pupil. Within this range the authors inferred a linear correlation between AMTF values and VA. In fact, the current findings would evidence a similar instance of linearity, provided only the values corresponding to the MIOLs were considered. With the incorporation of a reference monofocal lens, however, we included a focus with considerably better optical quality than any foci of the MIOLs. Compare, for instance, the AMTF scores for distance presented in Table 2 for the monofocal lens (71.22), with those of the other lenses: ZKB00 (29.10), ZLB00 (28.34), SV25T0 (44.09), ATLISA809 (28.98) and ATLISATri (27.69). In addition, the monofocal lens group showed considerably worse values of VA at near (median DCNVA of 0.40 logMAR) in comparison to the lowest values of VA (0.27 logMAR) described by Felipe et al (17). The extension of both ranges of AMTF and VA values disclosed a correlation between lens optical quality and VA that cannot be simply described by a linear function, as shown in Figure 2. Indeed, it may be observed that beyond a certain AMTF threshold (which corresponded to AMTF 20 in our experiments), higher AMTF values did not result in a noticeable increase in VA. Plaza-Puche et al (18) also described a linear model for the relationship between logMAR VA and their image quality metric (IQM), which predicted a value of VA of -0.2 logMAR for the best measured IQM of 0.92 . However, their best clinically measured VA was always equal or lower than 0.0 logMAR. This finding is not in disagreement with our results in the sense that beyond a certain level of optical quality, any further increase in AMTF does not produce any detectable improvement in the VA of the patients. Again, this fact gives support to the hypothesis that other ocular, optical and neuro-psychophysical factors may be playing a role and preventing any further increase in VA. 
Regarding intermediate distance, both AMTF and VA values were similarly compromised in all lens designs, with the monofocal lens displaying the worst DCIVA, as expected. Interestingly, the ATLISATri, with a $4.34 \mathrm{~mm}$ in diameter central trifocal diffractive region offering $+1.66 \mathrm{D}$ add power, was not found to perform better than any other MIOL designs in terms of DCIVA, although this lens presented the best AMTF value of all MIOLs at intermediate distance. These findings are in disagreement with those of Marques and Ferreira (26), who reported excellent distance, intermediate and near VA with the ATLISATri. The ZKB00, with low add power of $+2.75 \mathrm{D}$, was found to offer the best DCIVA. Finally, not unexpectedly, at the near focus, the worst AMTF values corresponded to the monofocal lens and to the distance dominant SV25T0; on the opposite, all the other MIOLs reached AMTF values over 20 (with the exception of the SV25T0). These findings were reflected in the values of DCNVA, in which statistically and clinically significant differences were encountered between the monofocal and multifocal lens designs, and between the SV25T0 and most of the other MIOLs. Carson and co-workers also reported worse objective image quality and VA at near and intermediate distances with the SV25T0 than with the ATLISATri (16). The best DCNVA was obtained with the ZLB00 followed by the ATLISA809, results that are consistent with the design of these lenses, which are intended to achieve a more balanced optical performance of their far and near foci.

It must be noted, however, that whereas the image obtained at the optical bench may allow for a direct comparison of retinal image quality, objective measurements not necessarily mimic the visual quality experienced by the patient, which also involves superior neural processing. Moreover, AMTF values 
were obtained at the best focus plane for each distance, with the corresponding adjustments for those IOLs without an intermediate or near focus, as described above; however VA was measured always at the same distances $(4 \mathrm{~m}, 60 \mathrm{~cm}$ and $40 \mathrm{~cm}$ for far, intermediate and near vision, respectively), regardless of actual lens addition for intermediate and/or near distances. In effect, this can be considered a source of uncertainty in most studies in which VA or other visual function parameters requiring the presentation of a test at a specific distance are compared among lens designs of different add powers characteristics. Also note that the AMTF metrics, obtained as an integral over 0-100 cycles/degree, are not equivalent to the VA metrics, which correspond to a more reduced range of spatial frequencies.

In conclusion, the present study revealed a nonlinear relationship between image quality measured at an optical bench and VA at distance, intermediate and near foci. The inclusion of a monofocal lens was useful to show that, beyond a certain AMTF threshold, any further increase in VA is probably prevented by other ocular, optical and neuro-psychophysical factors. 


\section{REFERENCES}

1. Lundström M, Barry P, Henry Y, Rosen P, Stenevi U. Evidence-based guidelines for cataract surgery: guidelines based on data in the European Registry of Quality Outcomes for Cataract and Refractive Surgery database. J Cataract Refract Surg. 2012;38:1086-1093.

2. Calladine D, Evans JR, Shah S, Leyland M. Multifocal versus monofocal intraocular lenses after cataract extraction. Cochrane Database Syst Rev. 2012; 9:CD003169.

3. de Vries NE, Nuijts RM. Multifocal intraocular lenses in cataract surgery: literature review of benefits and side effects. J Cataract Refract Surg. 2013;39:268-278.

4. Artigas JM, Menezo JL, Peris C, Felipe A, Díaz-Llopis M. Image quality with multifocal intraocular lenses and the effect of pupil size: comparison of refractive and hybrid refractive-diffractive designs. J Cataract Refract Surg. 2007;33:2111-2117.

5. Gil MA, Varon C, Rosello N, Cardona G, Buil JA. Visual acuity, contrast sensitivity, subjective quality of vision, and quality of life with 4 different multifocal IOLs. Eur J Ophthalmol. 2012;22:175-187.

6. Mester U, Hunold W, Wesendahl T, Kaymak H. Functional outcomes after implantation of Tecnis ZM900 and Array SA40 multifocal intraocular lenses. J Cataract Refract Surg. 2007;33:1033-1040. 
7. Gil MA, Varon C, Cardona G, Vega F, Buil J. Comparison of far and near contrast sensitivity in patients symmetrically implanted with multifocal and monofocal IOLs. Eur J Ophthalmol. 2014;24:44-52.

8. Cillino G, Casuccio A, Pasti M, Bono V, Mencucci R, Cillino S. Working-age cataract patients: visual results, Reading performance, and quality of life with three diffractive multifocal intraocular lenses. Ophthalmology. 2014;121:34-44.

9. Choi J, Schwiegerling J. Optical performance measurements and night driving simulation of ReSTOR, ReZoom and Tecnis multifocal intraocular lenses in a model eye. J Refract Surg. 2008;24:218-222.

10. Chiam PJT, Chan JH, Haider SI, Karia N, Kasaby H, Aggarwal RK. Functional vision with bilateral ReZoom and ReSTOR intraocular lenses 6 months after cataract surgery. J Cataract Refract Surg. 2007;33:2057-2061.

11. Gatinel D, Pagnoulle C, Houbrechts Y, Gobin L. Design and qualification of a diffractive trifocal optical profile for intraocular lenses. J Cataract Refract Surg. 2011;37:2060-2067.

12. Gatinel D, Houbrechts Y. Comparison of bifocal and trifocal diffractive and refractive intraocular lenses using an optical bench. J Cataract Refract Surg. 2013;39:1093-1099.

13. Pepose JS, Wang D, Altmann GE. Comparison of through-focus image sharpness across five presbyopia-correcting intraocular lenses. Am J Ophthalmol. 2012;154:20-28. 
14. Vega F, Alba-Bueno F, Millán MS, Varón C, Gil MA, Buil JA. Halo and through-focus performance of four diffractive multifocal intraocular lenses. Invest Ophthalmol Vis Sci. 2015;56:3967-3975.

15. Ruiz-Alcocer J, Madrid-Costa D, García-Lázaro S, Ferrer-Blasco T, MontésMicó R. Optical performance of two new trifocal intraocular lenses: throughfocus MTF and influence of pupil size. Clin Experiment Ophthamol. $2014 ; 42: 271-276$.

16. Carson D, Hill WE, Hong X, Karakelle M. Optical bench performance of AcrySof IQ ReSTOR, AT LISA tri, and FineVision intraocular lenses. Clin Ophthalmol. 2014;8:2105-2113.

17. Felipe A, Pastor F, Artigas JM, Diez-Ajenjo A, Gené A, Menezo JL. Correlation between optics quality of multifocal intraocular lenses and visual acuity. J Cataract Refract Surg. 2010;36:557-562.

18. Plaza-Puche AB, Alió JL, MacRae S, Zheleznyak L, Sala E, Yoon G. Correlating optical bench performance with clinical defocus curves in varifocal and trifocal intraocular lenses. J Refract Surg. 2015;31:300-307.

19. Vega F, Alba-Bueno F, Millán MS. Energy distribution between distance and near images in apodized diffractive multifocal intraocular lenses. Invest Ophthalmol Vis Sci. 2011;52:5695-5710.

20. Montés-Micó R, Madrid-Costa D, Ruíz-Alcocer J, Ferrer-Blasco T, Pons AM. In vitro optical quality differences between multifocal apodized diffractive intraocular lenses. J Cataract Refract Surg. 2013;39:928-936. 
21. International Organization for Standardization (ISO). ISO 11979-2:2014

Ophthalmic implants - intraocular lenses - Part 2: Optical properties and test methods. ISO. 2014.

22. Vega F, Millán MS, Wells B. Spherical lens versus aspheric artificial cornea for intraocular lens testing, Optics Lett. 2010;35:1539- 1541.

23. Simpson MJ. Diffractive multifocal intraocular lens image quality. Appl Opt. 1992;31:3621-3626.

24. Madrid-Costa D, Ruiz-Alcocer J, Ferrer-Blasco T, García-Lázaro S, MontésMicó R. Optical quality differences between three multifocal intraocular lenses: Bifocal low add, bifocal moderate add and trifocal. J Refract Surg. 2013;29:749754.

25. Rosser DA, Cousens SN, Murdoch IE, Fitzke FW, Laidlaw DA. How sensitive to clinical change are ETDRS logMAR visual acuity measurements? Invest Ophthalmol Vis Sci. 2003;44:3278-3281.

26. Marques EF, Ferreira TB. Comparison of visual outcomes of 2 diffractive trifocal intraocular lenses. J Cataract Refract Surg. 2015;41: 354-363. 


\section{TABLES}

Table 1. Characteristics of the intraocular lenses under evaluation (all IOLs had a base power of $20.00 \mathrm{D})$.

\begin{tabular}{|c|c|c|c|c|}
\hline LENS & $\begin{array}{c}\text { MANUFACTURE } \\
\text { R }\end{array}$ & $\begin{array}{l}\text { ADD POWER } \\
\text { (D) }\end{array}$ & $\begin{array}{l}\mathrm{SA} \ddagger \\
(\mu \mathrm{m})\end{array}$ & OPTICAL DESIGN \\
\hline $\begin{array}{c}\text { AcrySof ReSTOR } \\
\text { SV25T0 }\end{array}$ & $\begin{array}{c}\text { Alcon } \\
\text { Laboratories, Fort } \\
\text { Worth, TX, USA }\end{array}$ & +2.5 & -0.20 & $\begin{array}{l}\text { Bifocal, anterior aspheric } \\
\text { apodized diffractive (3.4 } \\
\mathrm{mm} \text { ) and refractive surface }\end{array}$ \\
\hline $\begin{array}{l}\text { Tecnis ZKB00 } \\
\text { Tecnis ZLB00 }\end{array}$ & $\begin{array}{l}\text { AMO Groningen, } \\
\text { The Netherlands }\end{array}$ & $\begin{array}{l}+2.75 \\
+3.25\end{array}$ & -0.27 & $\begin{array}{l}\text { Bifocal, anterior aspheric } \& \\
\text { posterior diffractive surface }\end{array}$ \\
\hline ATLISA 809 & Carl Zeiss & +3.75 & -0.18 & Bifocal, aspheric diffractive \\
\hline ATLISATri 839MP & $\begin{array}{l}\text { Meditec AG, } \\
\text { Jena, Germany }\end{array}$ & $\begin{array}{l}+3.33 \\
+1.66^{\dagger}\end{array}$ & -0.18 & $\begin{array}{l}\text { Trifocal, anterior surface } \\
\text { with a diffractive profile }\end{array}$ \\
\hline Tecnis ZA9003 & $\begin{array}{l}\text { AMO Groningen, } \\
\text { The Netherlands }\end{array}$ & ------- & -0.27 & Monofocal, aspheric \\
\hline
\end{tabular}

$\dagger$ Intermediate focus

‡ Spherical Aberration (value of the $\mathrm{c}(4,0)$ Zernike coefficient for a $6.0 \mathrm{~mm}$ pupil) 
Table 2. Demographic data, CDVA, DCIVA and DCNVA measurements and AMTF ( $3 \mathrm{~mm}$ pupil) for each lens type. Results are displayed as median and range (minimum; maximum). Also shown is the outcome of the Kruskal-Wallis test of statistical significance ( $x^{2}$ and $p$-value).

\begin{tabular}{|c|c|c|c|c|c|c|c|c|}
\hline & & $\begin{array}{c}\text { ZA9003 } \\
\text { monofocal }\end{array}$ & $\begin{array}{l}\text { ZKB00 } \\
\text { bifocal }\end{array}$ & $\begin{array}{l}\text { ZLB00 } \\
\text { bifocal }\end{array}$ & $\begin{array}{l}\text { SVT250 } \\
\text { bifocal }\end{array}$ & $\begin{array}{c}\text { ATLISA809 } \\
\text { bifocal }\end{array}$ & $\begin{array}{l}\text { ATLISATri } \\
\text { trifocal }\end{array}$ & $X^{2}(p)$ \\
\hline n (eyes) & & 18 & 12 & 18 & 16 & 9 & 6 & \\
\hline Age (years) & & $\begin{array}{c}72.5 \\
(60 ; 80)\end{array}$ & $\begin{array}{c}77 \\
(61 ; 84)\end{array}$ & $\begin{array}{c}71.5 \\
(67 ; 78)\end{array}$ & $\begin{array}{c}72 \\
(66 ; 84)\end{array}$ & $\begin{array}{c}69 \\
(68 ; 77)\end{array}$ & $\begin{array}{c}78 \\
(69 ; 82)\end{array}$ & $\begin{array}{c}5.148 \\
(0.398)\end{array}$ \\
\hline $\begin{array}{c}\text { Gender } \\
\text { (male/female) }\end{array}$ & & $10 / 8$ & $2 / 10$ & $7 / 11$ & $10 / 6$ & $0 / 9$ & $2 / 4$ & $\begin{array}{l}11.950 \\
(0.018)\end{array}$ \\
\hline IOL power (D) & & $\begin{array}{c}21.25 \\
(19 ; 23.5)\end{array}$ & $\begin{array}{c}22 \\
(20.5 \\
23)\end{array}$ & $\begin{array}{c}22.25 \\
(20 ; 24)\end{array}$ & $\begin{array}{c}20 \\
(17 ; 23)\end{array}$ & $\begin{array}{c}21.5 \\
(19 ; 22.5)\end{array}$ & $\begin{array}{c}21 \\
(20.5 ; 24)\end{array}$ & $\begin{array}{c}9.304 \\
(0.098)\end{array}$ \\
\hline $\begin{array}{l}\text { Pupil } \\
\text { diameter } \\
\text { (mm) }\end{array}$ & & $\begin{array}{c}3.5 \\
(3.4 ; 4.5)\end{array}$ & $\begin{array}{c}4 \\
(3.5 ; 4)\end{array}$ & $\begin{array}{c}4 \\
(3.5 ; 4)\end{array}$ & $\begin{array}{c}3.5 \\
(3.5 ; 4)\end{array}$ & $\begin{array}{c}3.5 \\
(3.5 ; 4)\end{array}$ & $\begin{array}{c}4 \\
(3.5 ; 4)\end{array}$ & \\
\hline & AMTF† & 71.22 & 29.10 & 28.34 & 44.09 & 28.98 & 27.69 & \\
\hline $\begin{array}{l}\text { Distance } \\
\text { Vision }\end{array}$ & $\begin{array}{c}\text { CDVA } \\
\text { (logMAR) }\end{array}$ & $\begin{array}{c}0.04 \\
(0.20 ; 0.00)\end{array}$ & $\begin{array}{c}0.02 \\
(0.14 ;- \\
0.02) \\
\end{array}$ & $\begin{array}{c}0.03 \\
(0.16 ;- \\
0.04) \\
\end{array}$ & $\begin{array}{c}0.02 \\
(0.06 ;- \\
0.08) \\
\end{array}$ & $\begin{array}{c}0.00 \\
(0.06 ;-0.02)\end{array}$ & $\begin{array}{c}0.07 \\
(0.10 ; 0.00)\end{array}$ & $\begin{array}{c}7.433 \\
(0.190)\end{array}$ \\
\hline \multirow[b]{2}{*}{$\begin{array}{l}\text { Intermediate } \\
\text { Vision }\end{array}$} & AMTF & 15.01 & 11.92 & 10.25 & 11.67 & 10.83 & 16.74 & \\
\hline & $\begin{array}{l}\text { DCIVAS } \\
\text { (logMAR) }\end{array}$ & $\begin{array}{c}0.35 \\
(0.66 ; 0.05)\end{array}$ & $\begin{array}{l}0.09 \\
(0.18 \\
0.00)\end{array}$ & $\begin{array}{l}0.14 \\
(0.22 \\
0.00)\end{array}$ & $\begin{array}{c}0.18 \\
(0.42 \\
0.09)\end{array}$ & $\begin{array}{c}0.27 \\
(0.36 ; 0.13)\end{array}$ & $\begin{array}{c}0.19 \\
(0.12 ; 0.22)\end{array}$ & $\begin{array}{c}60.903 \\
(<0.001)\end{array}$ \\
\hline & AMTF & 7.14 & 34.30 & 31.74 & 15.40 & 23.49 & 23.08 & \\
\hline Near Vision & $\begin{array}{l}\text { DCNVAT } \\
\text { (logMAR) }\end{array}$ & $\begin{array}{c}0.51 \\
(1.00 ; 0.19)\end{array}$ & $\begin{array}{c}0.11 \\
(0.30 \\
0.04)\end{array}$ & $\begin{array}{c}0.03 \\
(0.13 ;- \\
0.05) \\
\end{array}$ & $\begin{array}{c}0.24 \\
(0.44 ; \\
0.14)\end{array}$ & $\begin{array}{c}0.04 \\
(0.19 ; 0.01)\end{array}$ & $\begin{array}{c}0.15 \\
(0.19 ; 0.05)\end{array}$ & $\begin{array}{c}35.000 \\
(<0.001)\end{array}$ \\
\hline
\end{tabular}

$\dagger$ Area under the modulation transfer function curve

‡ Monocular corrected distance visual acuity

$\S$ Monocular distance corrected intermediate visual acuity

I DCNVA: Monocular distance corrected near visual acuity 


\section{FIGURES}

Fig 1 Optical setup used for objective imaging quality assessment / testing. a) general view; b) Scheme of the optical setup, inset I: trifocal diffractive MIOL, inset II: bifocal diffractive MIOL

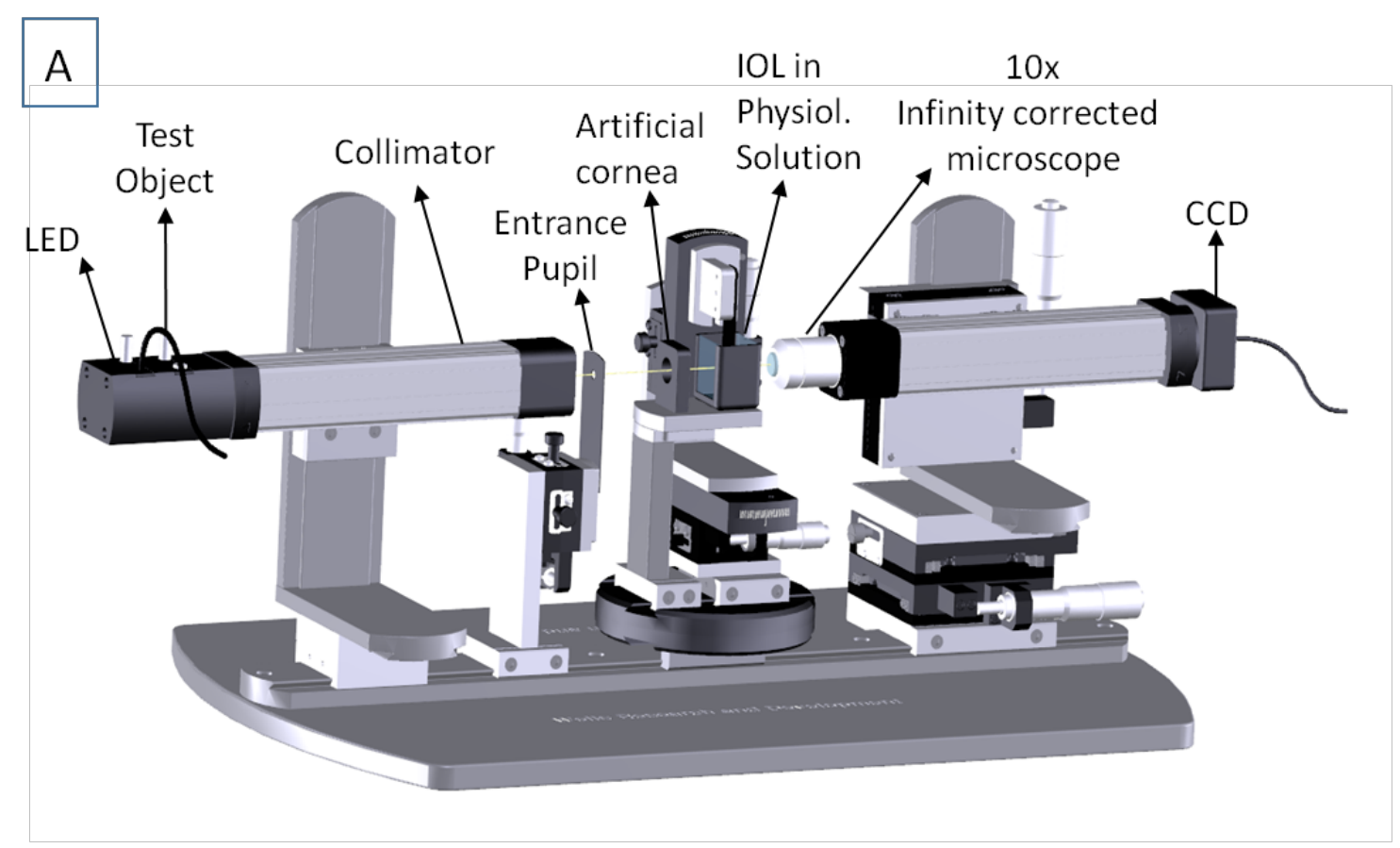




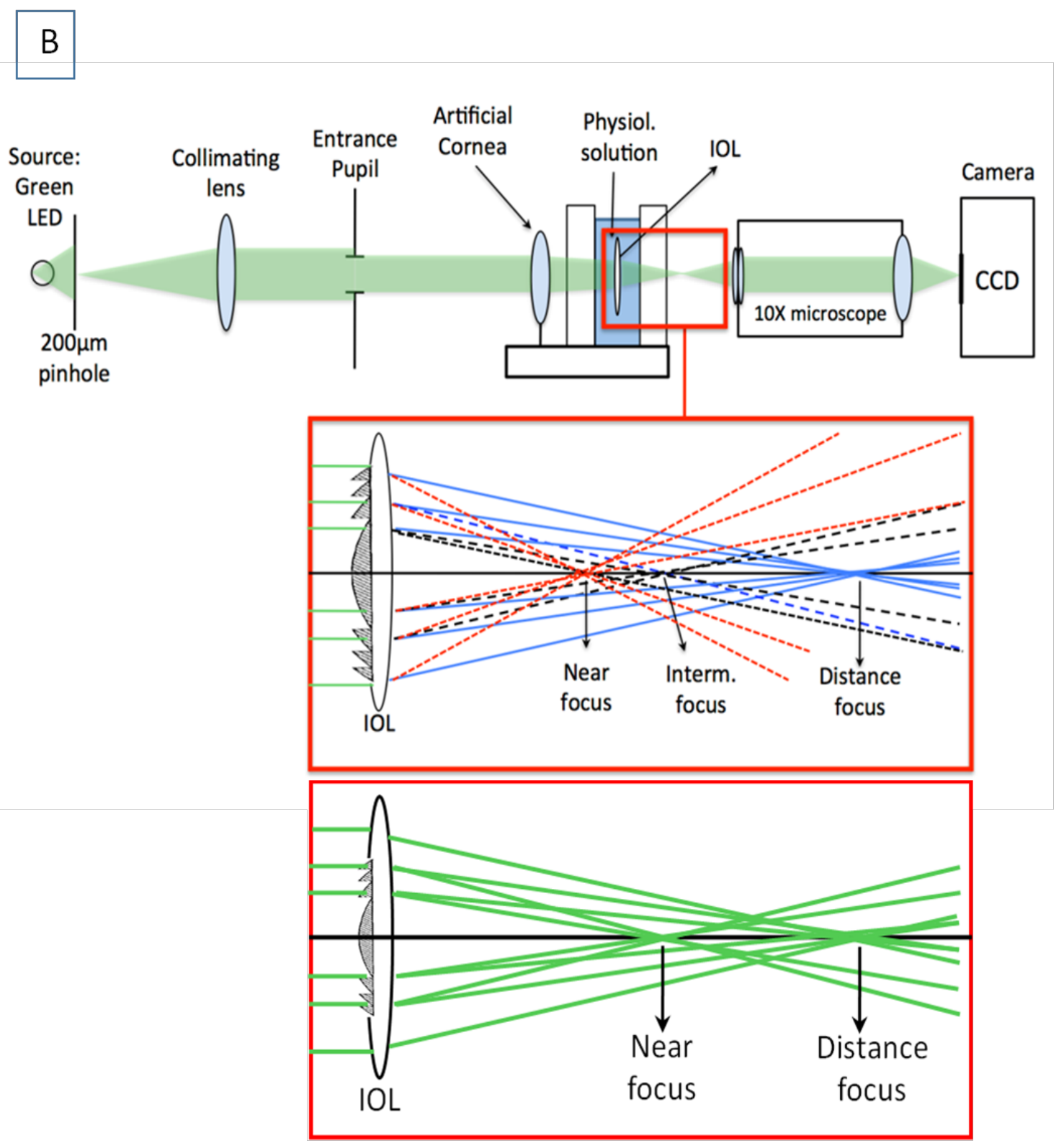


Fig 2 Distance, intermediate and near visual acuity and area under the MTF (AMTF) values. Filled squares: monofocal ZA9003; filled circles: bifocal SVT250; blank squares: rest of the IOLs

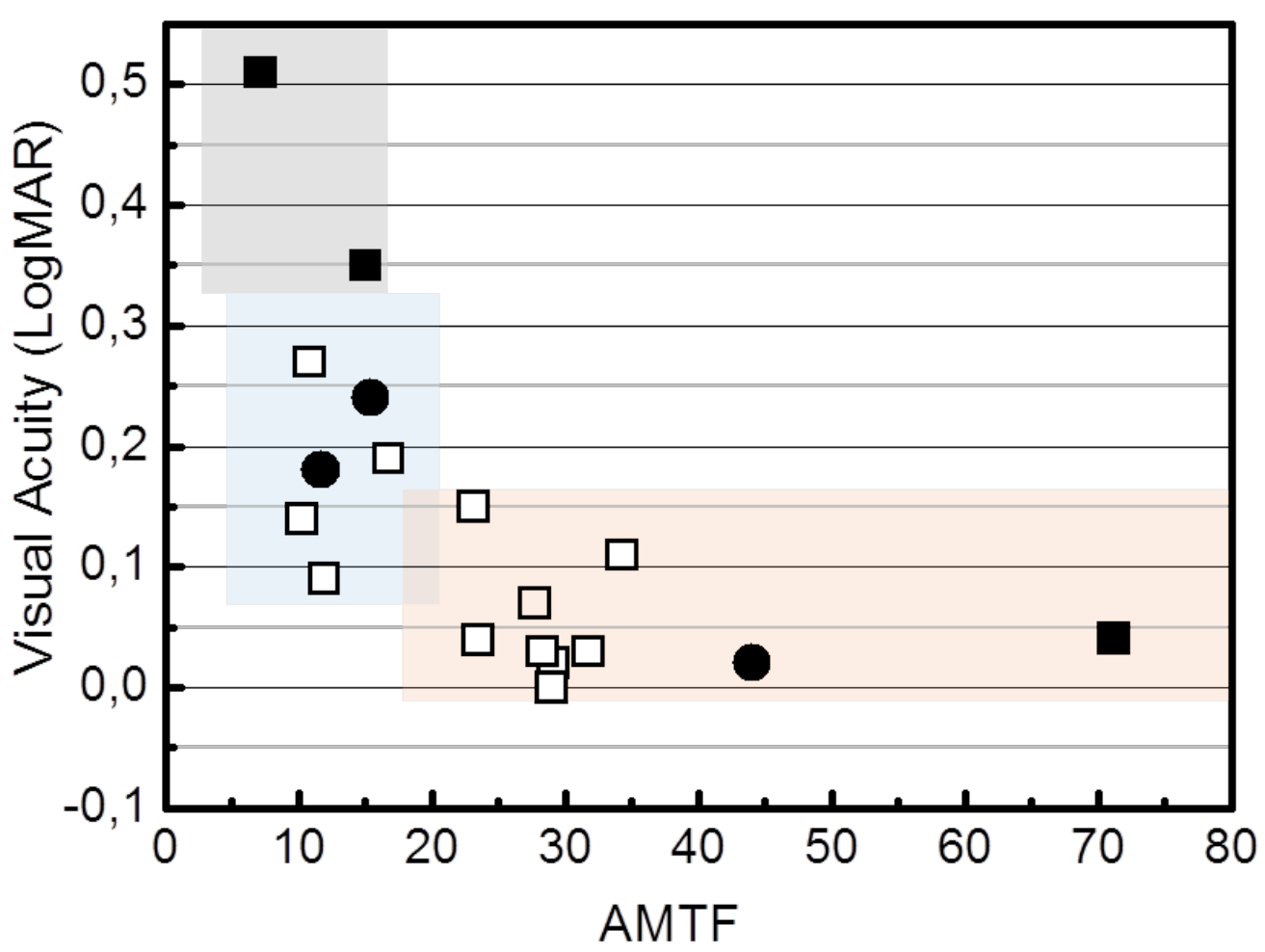

